\title{
The U.S. Supreme Court is about to re-evaluate how some states carry out lethal injections.
}

\begin{abstract}
Next month, the Supreme Court will hear oral arguments in a case which challenges Oklahoma's use of "liquid fire" in executions. The drug - potassium chloride - is one of a cocktail of drugs currently used in some states to carry out death sentences, a cocktail that has led to botched executions. Nancy E. Millar comments on the upcoming case, which challenges the drug's use under the Eighth Amendment's prohibition of cruel and unusual punishment. She writes that while it is impossible to predict what the Court will decide, its previous decisions and statements might provide some indication of how the justices are leaning.
\end{abstract}

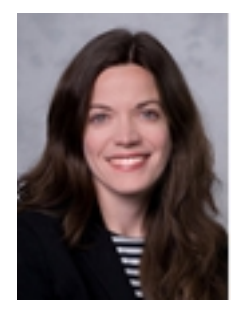

In January, the U.S. Supreme Court granted certiorari (review) on an important case that will force it to reexamine, and perhaps reconfigure, the troubled lethal injection landscape. The case, Glossip v. Gross, challenges Oklahoma's use of a three-drug protocol to carry out its executions and follows a recent spate of botched executions.

In April last year Oklahoma used midazolam as the first drug in its three-drug sequence for the first time. That execution, of Clayton Lockett, has been called a "bloody mess" and widely condemned as one of a series of badly botched executions to be carried out in several states over the past year. In the words of Justice Sonia Sotomayor, during the Lockett execution, he "awoke and writhed on the execution table for some time after the drugs had been injected and officials confirmed him to be unconscious. He was overheard to say, "Something is wrong,"” and, "'The drugs aren't working." . . . Eventually, some 40 minutes after the lethal injection drugs were administered, Lockett died."

Oklahoma planned to execute Charles F. Warner via the same three-drug method shortly after executing Lockett, but postponed the Warner execution in light of the problems. This gave the lawyers for Mr. Warner and three other prisoners time to ask the Court to stay their scheduled executions—but the Court declined to do so. Consequently in January, Oklahoma executed Mr. Warner using the same three-drug protocol that had caused an uproar in Lockett's death. Less than two weeks later, the Court granted certiorari in Glossip in order to review the constitutionality of that protocol. The Court subsequently stayed the three other prisoners' scheduled executions.

The petitioners in Glossip-death-sentenced prisoners awaiting execution in Oklahoma-argue to the Court in their brief, filed on March 9, that the use of the three-drug protocol violates the Eighth Amendment's prohibition of cruel and unusual punishment. Because midazolam does not produce a "deep, comalike unconsciousness," they argue, it leaves prisoners vulnerable to experiencing "constitutionally intolerable" pain and suffering. Potassium chloride, the third drug in the protocol, feels like "liquid fire" when injected into a person who has not been already rendered deeply unconscious, the petitioners claim, and "injecting a prisoner with liquid fire is just as unconstitutional as lighting him afire."

The Supreme Court has not addressed the constitutionality of a lethal injection protocol since Baze $v$. Rees in 2008. In Baze, the Court ruled that the three-drug cocktail at issue in that case-the sedative sodium thiopental, the paralytic pancuronium bromide, and heart-stopping potassium chloride-did not violate the Eighth Amendment. However, the Court found it uncontested that, "failing a proper dose of sodium thiopental that would render the prisoner unconscious, there is a substantial, constitutionally unacceptable risk of suffocation from the administration of pancuronium bromide and pain from the injection of potassium chloride."

Seven years later, in Glossip, the Court faces just such a scenario: Because midazolam now has failed to render at least two prisoners unconscious, in the Wood and Lockett executions, the Court must squarely confront the situation it deemed "constitutionally unacceptable" in Baze. 


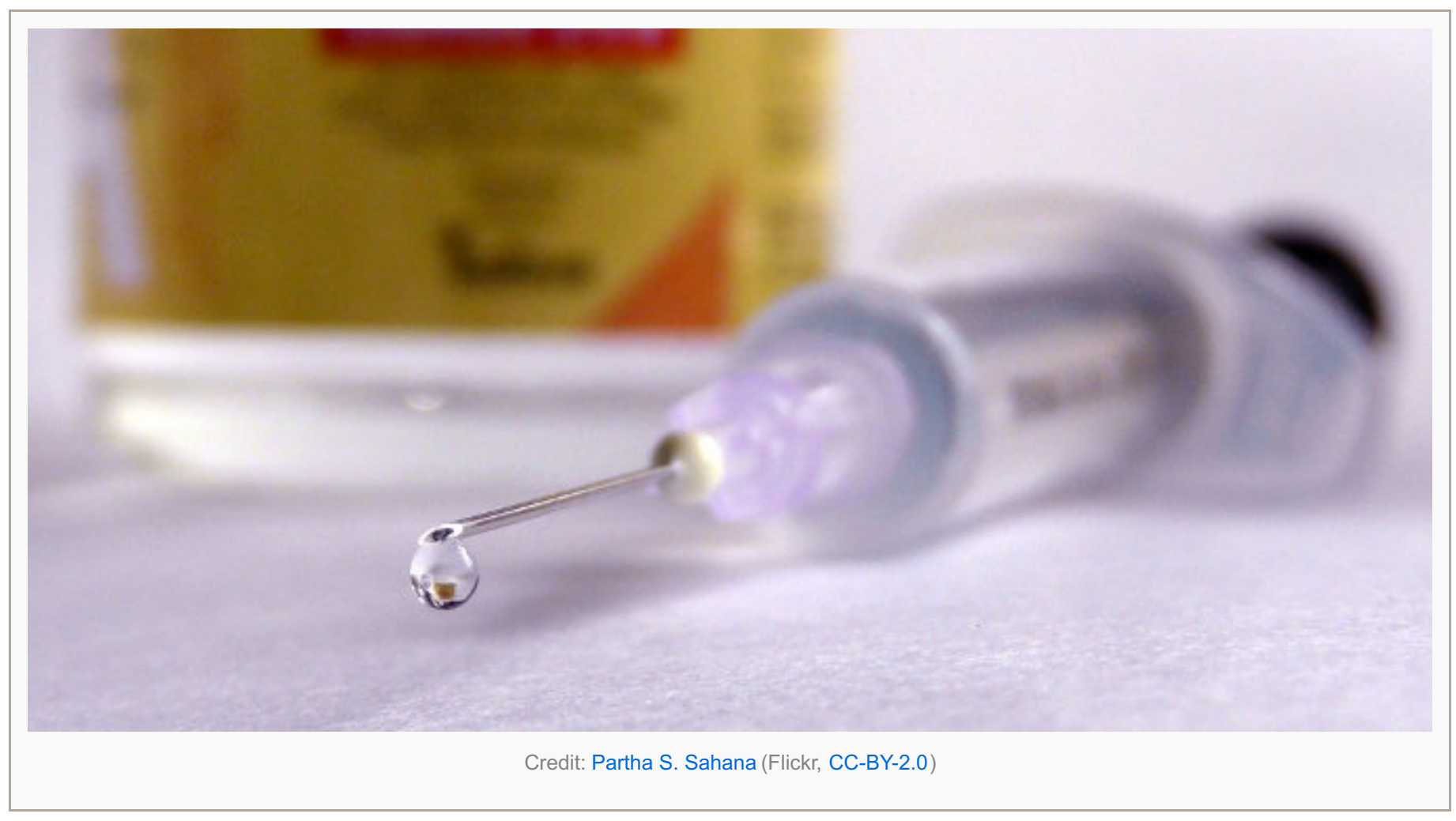

While it is impossible to predict precisely what the Court will decide, it is instructive to look to previous decisions and other indications of the justices' leanings to date.

Baze was a split decision with only three justices signing on to the majority's reasoning, but seven total justices agreeing with the judgment. Chief Justice John G. Roberts Jr. wrote the majority opinion in Baze, joined by Justices Anthony M. Kennedy and Samuel Anthony Alito Jr. Baze established that, to prevail on an Eighth Amendment claim, a prisoner must demonstrate a "'substantial risk of serious harm,' an 'objectively intolerable risk of harm' that prevents prison officials from pleading that they were 'subjectively blameless for purposes of the Eighth Amendment." Ruling on the narrow issues presented in Baze, the majority held that the petitioners did not show that the risk of an inadequate dose of the first drug in Kentucky's three-drug cocktail was substantial and rejected the argument that the Eighth Amendment required Kentucky to adopt alternative procedures identified by petitioners.

Justice John Paul Stevens concurred in the judgment, but warned that the majority opinion would "generate debate not only about the constitutionality of the three-drug protocol, and specifically about the justification for the use of the paralytic agent, pancuronium bromide, but also about the justification for the death penalty itself." He noted that pancuronium bromide was so widely recognized as causing extreme pain in a conscious patient that several states had enacted legislation prohibiting its use in animal euthanasia.

Justice Clarence Thomas wrote his own concurring opinion, joined by Justice Antonin Scalia, disagreeing with the majority's statement of the governing Eighth Amendment standard but agreeing with the judgment. Under Justice Thomas's interpretation of the Constitution, "a method of execution violates the Eighth Amendment only if it is deliberately designed to inflict pain."

Justice Breyer also concurred, agreeing with the judgment only and approving of the standard suggested by Justice Ruth Bader Ginsburg in her dissent: To determine the constitutionality of an execution procedure, a court should examine "whether the method creates an untoward, readily avoidable risk of inflicting severe and unnecessary suffering." Under this proposed test, the Court would examine three factors: the "degree of risk," the "magnitude of pain," and the "availability of alternatives." Justice David H. Souter joined Justice Ginsburg's dissent.

Justices Stevens and Souter are no longer on the Court, replaced by Justices Sotomayor and Kagan . Both new justices, along with Justices Ginsburg and Breyer, would have stayed the executions of Warner and the others when they filed their application in mid-January. (Notably, five votes are required to stay an execution, while four 
votes are sufficient to grant certiorari; thus, Oklahoma executed Warner even though the Court decided to review the state's protocol.)

It is clear that Justices Sotomayor, Kagan, and Ginsburg will side with the petitioners in Glossip, while Justices Thomas and Scalia will not. Given Justice Breyer's agreement with delaying the Warner and Gross's executions, and his approval of the standard announced by Justice Ginsburg in Baze, he is expected to agree with the petitioners' arguments against the constitutionality of Oklahoma's protocol. Justices Roberts, Kennedy, and Alitothe only three Justices who supported Baze's judgment and reasoning—stand somewhere in the middle.

Last year, in Wood v. Ryan, a First Amendment challenge to Arizona's secrecy about the drugs that were to be used in Mr. Wood's then-scheduled execution, Ninth Circuit Judge Alex Kozinski dissented from that Court's denial of rehearing en banc, noting that:

Whatever happens to Wood, the attacks [on lethal injection] will not stop and for a simple reason: The enterprise is flawed. Using drugs meant for individuals with medical needs to carry out executions is a misguided effort to mask the brutality of executions by making them look serene and peaceful-like something any one of us might experience in our final moments. But executions are, in fact, nothing like that. They are brutal, savage events, and nothing the state tries to do can mask that reality. Nor should it. If we as a society want to carry out executions, we should be willing to face the fact that the state is committing a horrendous brutality on our behalf.

Next month, the Supreme Court will squarely confront yet another attack on the U.S. lethal injection landscape, following a series of executions where the brutality and savagery of the method were on full display.

Please read our comments policy before commenting.

Note: This article gives the views of the author, and not the position of USApp-American Politics and Policy, nor of the London School of Economics.

Shortened URL for this post: http://bit.ly/1xfk0Cm

\section{About the author}

\section{Nancy E. Millar- Arizona Summit Law School}

Nancy E. Millar is an Assistant Professor of Law at Arizona Summit Law School in Phoenix. Her research interests include the death penalty, criminal law, international human rights, and women's rights. Follow her @LPprof.

- CC BY-NC-ND 3.02014 LSE USAPP

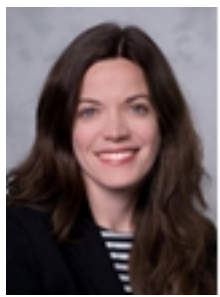

